\title{
Effect of extreme heat processing on the Moroccan Zantaz' honey antioxidant activities
}

\author{
Youssef Elamine $^{1,2}$ - Ofelia Anjos ${ }^{3,4,5} \cdot$ Leticia M. Estevinho $^{6} \cdot$ Badiâa Lyoussi $^{1}$ \\ Smail Aazza $^{1,7} \cdot$ Maria G. Miguel $^{2}$
}

Revised: 1 March 2020/ Accepted: 18 March 2020

(C) Association of Food Scientists \& Technologists (India) 2020

\begin{abstract}
The effect of an extreme heat processing on Zantaz honey samples was studied using a panel of physicochemical parameters, antioxidant activities and FTIR-ATR spectroscopy. Honey samples were heated at $121^{\circ} \mathrm{C}$ for $30 \mathrm{~min}$ and the heat processing effect was confirmed indirectly through the assessment of hydroxymethylfurfural content, for which the values increased significantly $(p<0.01)$, and diastase activity, which was totally absent after the thermal processing. Besides, the effects of the heat on the antioxidant activities were diverse. Indeed, while the ability to scavenge $2,2^{\prime}$-azinobis(3-ethylbenzothiazoline-6-sulphonic acid cation radicals $\left(\mathrm{ABTS}^{+}\right.$) and 2,2-diphenyl-1-picrylhydrazyl radicals was
\end{abstract}

Ofelia Anjos

ofelia@ipcb.pt

Youssef Elamine

elamineysef@gmail.com

Leticia M. Estevinho

leticia@ipb.pt

Badiâa Lyoussi

lyoussi@gmail.com

Smail Aazza

aazzasmail@ymail.com

Maria G. Miguel

mgmiguel@ualg.pt

1 Laboratory of Physiology-Pharmacology-Environmental Health, Faculty of Sciences Dhar El Mehraz, University Sidi Mohamed Ben Abdallah, BP 1796, 30000 Atlas, Fez, Morocco

2 Departamento de Química e Farmácia, Faculdade de Ciências e Tecnologia, MED - Mediterranean Institute for Agriculture, Environment and Development, Universidade do Algarve, Campus de Gambelas, 8005-139 Faro, Portugal enhanced $\left(p<0.05\right.$ only for $\left.\mathrm{ABTS}^{+}\right)$, after the heat processing, nitric oxide radicals scavenging activity was reduced drastically $(p<0.01)$. Regarding the chelating power, it was totally abolished following heating. Other activities showed no significant alteration. The initial values of antioxidant activities seem to be determinant in the changes occurring after the heat processing. Amongst the analysed parameters, following the heat processing, the honey colour was the variable where the influence of baseline values was the greatest. The spectral analyses confirmed that FTIR-ATR is a useful technique to discriminate the chemical differences occurring in honey after heat processing.
3 Instituto Politécnico de Castelo Branco, 6001-909 Castelo Branco, Portugal

4 Centro de Estudos Florestais, Instituto Superior de Agronomia, Universidade de Lisboa, Tapada da Ajuda, 1349-017 Lisbon, Portugal

5 Centro de Biotecnologia de Plantas da Beira Interior, 6001-909 Castelo Branco, Portugal

6 Centro de Investigação de Montanha (CIMO), Instituto Politécnico de Bragança, 5300-252 Bragança, Portugal

7 Laboratory of Phytochemistry, National Agency of Medicinal and Aromatic Plants, BP 159, Taounate, Morocco 
Keywords Honey · Heat processing - Antioxidant activities · Flavonoids content · FTIR-ART

\section{Introduction}

The most important factors influencing honey marketing are those that are easily evaluated by customers, including rheology (the ability of honey to crystallize), colour and shelf-lifetime. Having those characteristics into consideration, honey heating used to be a common practice to reach the desired rheological properties thereby avoiding the crystallization process as well as to increase the shelflifetime by elimination possible contaminant microorganisms (Abu-Jdayil et al. 2002; Tosi et al. 2002).

In spite of the theoretical benefits of heating, it is important to mention that during thermal processing the composition of honey undergoes a series of changes that are linked to the interactions between its major (sugars) and minor (amino acids) compounds. Those reactions include the conversion of organic acids to alcohols or that of polyphenolic compounds into volatiles or even degradation of compounds like vitamins (da Silva et al. 2016). One of the reactions is the non-enzymatic browning, Maillard reaction, which in the ultimate stages, the degradation of Amadori products occur and generate Strecker aldehydes, pyrazines, pyrroles and furans, amongst others (Turkmen et al. 2006). The condensation of the generated active molecules with amino-acids form high molecular weight brown polymers known as melanoidins (Brudzynski and Miotto 2011a). Hydroxymethylfurfural (HMF) is considered to be the most important product and is therefore used for the confirmation of honey freshness when its values do not exceed $40 \mathrm{mg} / \mathrm{kg}$ (Turhan et al. 2008). In addition, in a recent review made by Shapla et al. (2018) about the influence of HMF levels present in honey on human health, the authors reported that it remains inconclusive because this compound has been described as exerting pernicious effects, such as mutagenic, genotoxic, organotoxic and enzyme inhibitory activities; but also beneficial effects including antioxidant, anti-allergic, anti-inflammatory, anti-hyperuricemic, and anti-hypoxic activities.

Several studies analysed the thermal effects on honey by evaluating the antioxidant activities and proved that the content of melanoidins correlated positively with honey antioxidant activity. The formation of melanoidins also explained the acquired activity after the heat processing (Brudzynski and Miotto 2011b, c). The observed increase depends on heat processing degree, and showed different behaviours towards different temperatures and heating times (Turkmen et al. 2006). Another influencing factor is honey botanic and geographical origin (Escuredo et al.
2019). In their studies about the effect of melanoidins formation on honey antioxidant activity after heat processing, Brudzynski and Miotto (2011c) observed that this phenomenon was more pronounced in light-coloured honey than in the dark-coloured samples.

While the increase in melanoidins' content is shown to increase the ability of honey to scavenge the free radicals used in the ORAC (Oxygen Radical Absorbance Capacity) assay (Brudzynski and Miotto 2011c), the degradation of other bioactive molecules may affect negatively the antioxidant ability toward other assays. Nagai et al. (2001) reported that the antioxidant activity of honey samples, determined using a linoleic acid-based lipid peroxidation assay, was drastically decreased following thermal treatment. The same authors linked the observed decrease to the decomposition of vitamins $\mathrm{B} 1, \mathrm{~B} 2$, and $\mathrm{C}$, and the destruction of catalase and peroxidase.

With the aim of better understanding heat effects on honey, we studied eight Zantaz honey samples produced in Morocco, mainly from Bupleurum spinosum. This honey was characterized in two previous contributions by the same group (Elamine et al. 2018, 2019). The collected samples have been characterized regarding their physicochemical properties and antioxidant activities, before and after the heat processing at $121{ }^{\circ} \mathrm{C}$ during $30 \mathrm{~min}$. To estimate the antioxidant activity it were used some of the most commonly employed assays like radical scavengers, metal-chelators and hydrogen donating agents (Brudzynski and Miotto 2011a). The physicochemical characteristics were studied using spectroscopic methods among which Fourier-transform infrared-attenuated total reflection, which has the advantage of being a non-destructive technique that only needs very small amounts of sample (Salvador et al. 2019).

\section{Materials and methods}

\section{Reagents and instruments}

Sodium phosphate, sodium hydroxide, and sodium carbonate were purchased from Pronalab, Madalena, Portugal; hydrochloric acid was provided by Fisher Scientific UK Ltd, Loughborough, UK; Acetic acid, Ascorbic acid, Folin-Ciocalteu, fuchsin, potassium hydroxide, methanol, and 2-propanol were provided by Merck KGaA products, Darmstadt, Germany; 2,2'-azino-bis(3-ethylbenzothiazoline-6-sulphonic acid), ferrozine, ferrous sulfate, gallic acid, nitroblue tetrazolium (NBT), ninhydrine, phenazine methosulfate (PMS), and proline were purchased from Acros Organics, New Jersey, USA; aluminium chloride and acetic anhydride provided by Panreac Química, MontcadaReixac, Barcelona, Spain; catechin was 
purchased from Fluka. Biochemika. Sigma-Aldrich. Steinheim, Germany; sulfuric acid, sodium acetate, starch, potassium iodide, iodine, and sodium nitroprusside were obtained from Riedel-de-Haen, Germany; microplate reader (Tecan Infinite M200, Tecan, Austria); analytical balance (Shimadzu, Aux 220, Philippines); electric furnace (Cassel, Portugal); Abbe Refractometer (HANNA, HI968601, Romania); High Performance Liquid Chromatography (Hitachi, LaChrom Elite, Japan); Optic microscope (Leitz Messtechnik GmbH, Wetzlar, Germany); Alpha FTIR-ATR spectrometer (Bruker, Germany); Shimadzu 160-UV spectrophotometer (Naab, Tamame, \& Caccavari).

\section{Sample preparation}

In this study, eight monofloral honey samples (classified as monofloral according the methodology proposed by Elamine et al. (2019) purchased from local Moroccan beekeepers were used. Each honey sample was divided into two aliquots: half was kept at room temperature and studied within 1 week $(\mathrm{n}=8)$; and half were heat processed at $121{ }^{\circ} \mathrm{C}$ for $30 \mathrm{~min}(\mathrm{n}=8)$. Both raw and heattreated samples were prepared in distilled water $(50 \%, \mathrm{w} / \mathrm{v})$ and centrifuged at $5000 \mathrm{~g}, 20 \mathrm{~min}$. The temperature, the heating period as well as preparation of samples were selected based on a previous work claiming that the conditions were sufficient to increase the degree of browning in both light- and medium-coloured honeys (Brudzynski and Miotto 2011b). All measurements were performed in triplicate and the results were presented as mean $\pm \mathrm{SD}$ (standard deviation).

\section{Pollen analysis}

The qualitative and quantitative analysis of pollen spectrum was accomplished following the International Commission for Bee Botany (ICBB) method, as described previously (Louveaux et al. 1978). An optic microscope with $400 \times$ and $1000 \times$ objectives, was used for pollen identification and count. One thousand pollen grains were counted for each sample, and the frequent classes were determined twice. A pollen species was considered dominant, when it represents more than $45 \%$ from the pollen spectrum, secondary with percentage between 16 and $45 \%$, important minor pollen from 3 to $15 \%$ and minor pollen when it is less than $3 \%$.

\section{Physicochemical parameters}

\section{Preliminary characterization}

Moisture, diastase activity, HMF and proline content were assessed following the Harmonized Methods of the International Honey Commission (Bogdanov et al. 2009).

\section{Colour, and melanoidins estimation}

Colour and melanoidins estimations were determined by measuring the absorbance of aqueous solutions ( $10 \mathrm{~g}$ of honey in $20 \mathrm{~mL}$ of distilled water) at three wavelengths by using Shimadzu 160-UV spectrophotometer. The $\mathrm{mm}$ Pfund values of honey samples were obtained using the following algorithm: $\mathrm{mm}$ Pfund $=-38.7+371.39 \times$ $\mathrm{A}_{635}$ (Naab et al. 2008). Melanoidins content was estimated based on the browning index (net absorbance $=\mathrm{A}_{450}-\mathrm{A}_{720}$ ) (Brudzynski and Miotto 2011c). Spectrophotometric measurements were performed in a $1 \mathrm{~cm}$ quartz cell; results were expressed as absorbance units (AU).

\section{Polyphenols, flavonoids and antioxidant activities}

\section{Polyphenols}

The total polyphenolic content (TPC) was determined in honey solutions using the Folin-Ciocalteau method (Singleton and Rossi 1965). To eliminate a possible interference of sugars in the assay, sugar solutions were made considering the sugar profile of each $50 \%$ honey sample solution $(\mathrm{w} / \mathrm{v})$, used for the estimation of polyphenols content. The assay was made for both honey and sugar solutions, and the results were expressed as mean of gallic acid equivalent (GAE) $\mathrm{mg} \pm \mathrm{SD}$ (standard deviation)/ $100 \mathrm{~g}$ honey, after the elimination of sugar interference. This interference was eliminated as follows: $\mathrm{Abs}=\mathrm{Abs}$ $(\mathrm{H})-\operatorname{Abs}(\mathrm{S})$, where Abs is the absorbance considered for the calculation of the polyphenolic content; $\mathrm{Abs}(\mathrm{H})$ is the absorbance of the honey solution and the Abs (S) is the absorbance of the sugar solution.

\section{Flavonoids}

The total flavonoid content (TFC) of different honey samples was determined using the aluminium chloride assay according to Samatha et al. (2012). To study a possible interference of sugars in this assay the sugar solution made for polyphenols content estimation was also used. To avoid possible interaction of sample colour with the reaction's reagents, the blank was constituted by water (substituting the other components of the reaction) plus the sample as reported by Sancho et al. (2016). The resulting 
absorbance was subtracted from the whole reaction absorbance before TFC estimation. The TFC was expressed in $\mathrm{mg}$ of catechin equivalents (CE) per $100 \mathrm{~g}$ of honey as the mean of three triplicate $\pm \mathrm{SD}$.

\section{Total antioxidant activity by ammonium molybdate reduction method}

Total antioxidant activity (TAA) was measured in different concentrations of samples according to the described by Prieto et al. (1999). Honey solution was mixed with $3 \mathrm{~mL}$ of reagent solution (0.6 M sulphuric acid, $28 \mathrm{mM}$ sodium phosphate and $4 \mathrm{mM}$ ammonium molybdate). After $90 \mathrm{~min}$ incubation at $95{ }^{\circ} \mathrm{C}$, the samples were cooled at room temperature and their absorbance values were measured at $695 \mathrm{~nm}$ in Shimadzu 160-UV spectrophotometer. The antioxidant activity was expressed as the number of ascorbic acid equivalents (AAE)/100 $\mathrm{g}$ of honey.

\section{DPPH (2,2-diphenyl-1-picrylhydrazyl) free radical scavenging activity}

Fifty microliters of each sample at different concentrations was placed in a cuvette, and $2 \mathrm{~mL}$ of $60 \mu \mathrm{M}$ methanolic solution of DPPH was added (Brand-Williams et al. 1995). After $60 \mathrm{~min}$ incubation at room temperature, absorbance measurements were made at $517 \mathrm{~nm}$ using Shimadzu 160-UV spectrophotometer (Tokyo, Japan). The percentage of inhibition of free radicals was calculated following the formula: $\left[\left(A_{0}-A_{1} / A_{0}\right) \times 100\right] . A_{0}$ is the absorbance of the negative control (blank sample containing the same amount of water and DPPH solution); $\mathrm{A}_{1}$ is the absorbance of the sample. The $\mathrm{IC}_{50}$ was then determined from the resulting concentration-inhibition percentage plot, as honey concentration inhibiting $50 \%$ of the generated free radicals and was expressed as $\mathrm{mg} / \mathrm{mL}$.

\section{ABTS $^{+}$(2,2'-azino-bis(3-ethylbenzothiazoline-6-sulphonic acid) free radical scavenging activity}

The determination of $\mathrm{ABTS}^{+}{ }^{+}$radical scavenging capacity was carried out as reported previously (Miguel et al. 2010). The reaction of $\mathrm{ABTS}^{+}$aqueous solution $(7 \mathrm{mM})$ with potassium persulfate $\left(\mathrm{K}_{2} \mathrm{~S}_{2} \mathrm{O}_{8}\right)(2.45 \mathrm{mM})$ was done in the dark, for $16 \mathrm{~h}$ to generate $\mathrm{ABTS}^{+}$free radical. The absorbance of the resulted solution was adjusted to 0.7 at $734 \mathrm{~nm}$. Twenty-five $\mu \mathrm{L}$ of honey dilutions were added to $275 \mu \mathrm{L} \mathrm{ABTS}^{+}$and the absorbance was read at $734 \mathrm{~nm}$, after $6 \mathrm{~min}$ incubation. The $\mathrm{IC}_{50}$ values were calculated from three replications and the results were expressed as mean $\pm \mathrm{SD}(\mathrm{mg} / \mathrm{mL})$.

\section{Reducing power}

The reducing power of honey samples was evaluated as described previously (Chu et al. 2000). In brief, honey solution in phosphate buffer $(0.2 \mathrm{M}, \mathrm{pH}$ 6.6) was added to $0.5 \mathrm{~mL}$ of potassium ferricyanide $(1 \%)$, and the mixture was incubated at $50{ }^{\circ} \mathrm{C}$ for $20 \mathrm{~min}$. After the incubation trichloroacetic acid solution (TCA) $(10 \%)$ was added to the mixture. A centrifugation at $600 \mathrm{~g}$ was applied for $10 \mathrm{~min}$, and the supernatant was mixed with $\mathrm{H}_{2} \mathrm{O}$ and ferric chloride solution $(0.1 \%)$ for $10 \mathrm{~min}$. The absorbance was measured at $700 \mathrm{~nm}$. Results were expressed as the absorbance of the reaction at the highest honey concentration.

\section{Chelating metal ions}

The chelating ability of honey samples against ferrous ions was evaluated as previously described in detail (Miguel et al. 2010). Briefly, honey solutions [different dilutions starting from $50 \%(\mathrm{w} / \mathrm{v})$ solution] were incubated with $50 \mu \mathrm{L}$ of iron(II) chloride, $\mathrm{FeCl}_{2}(2 \mathrm{mM})$. The reaction was initiated by the addition of $200 \mu \mathrm{L}$ ferrozine $5 \mathrm{mM}$, and after $10 \mathrm{~min}$, the absorbance at $562 \mathrm{~nm}$ was measured. The $\mathrm{IC}_{50}$ values were calculated and expressed as mean $\pm \mathrm{SD}$ $(\mathrm{mg} / \mathrm{mL})$ of three replicates.

\section{Nitric oxide (NO) scavenging activity}

The protocol was initiated by generating $\mathrm{NO}$ radicals from sodium nitroprusside ( $\mathrm{SNP})\left(\mathrm{Na}_{2}\left[\mathrm{Fe}(\mathrm{CN})_{5} \mathrm{NO}\right]\right)$ and was measured by using the Griess reagent ( $N$-(1-Naphthyl) ethylenediamine) (Ho et al. 2010). Briefly, $50 \mu \mathrm{L}$ of serially diluted honey solutions were added to $50 \mu \mathrm{L}$ of $10 \mathrm{mM}$ SNP in phosphate buffer saline (PBS) into a 96-well plate, and incubated at room temperature for $90 \mathrm{~min}$. Finally, the remaining free fraction of NO radicals was revealed by adding $50 \mu \mathrm{L}$ Griess reagent and absorbance was measured at $546 \mathrm{~nm}$. The $\mathrm{IC}_{50}$ was calculated with slight different of what was explained in DPPH section: $\left[1-\left(\mathrm{A}_{\text {sample }}-\mathrm{A}_{\text {sample }} \quad\right.\right.$ blank $) /\left(\mathrm{A}_{\text {control }}-\mathrm{A}_{\text {con- }}\right.$ trol blank $)] \times 100$, where $\left(\mathrm{A}_{\text {sample }}-\mathrm{A}_{\text {sample blank }}\right)$ is the difference in the absorbance of a sample, with or without $10 \mathrm{mM} \mathrm{SNP}$, and $\left(\mathrm{A}_{\text {control }}-\mathrm{A}_{\text {control blank }}\right)$ is the difference in the absorbance of the PBS control, with or without $10 \mathrm{mM}$ SNP.

Superoxide anion radical $\left(\mathrm{O}_{2}^{--}\right)$scavenging activity (nonenzymatic method)

Superoxide anion radical $\mathrm{O}_{2}^{--}$ions were generated in a nonenzymatic phenazine methosulfatenicotinamide adenine dinucleotide (PMS-NADH) system based on the oxidation 
of NADH and assayed by reduction of nitroblue tetrazolium (NBT) (Albano and Miguel 2011). Honey solutions $(25 \mu \mathrm{L})$ were mixed with $25 \mu \mathrm{L}$ nitroblue tetrazolium $(0.42 \mathrm{mg} / \mathrm{mL})$ and $25 \mu \mathrm{L}$ NADH $(1.32 \mathrm{mg} / \mathrm{mL})$ and $\mathrm{H}_{2} \mathrm{O}$ $(125 \mu \mathrm{L})$ followed by $25 \mu \mathrm{L}$ phenazine methosulfate (PMS) $(0.25 \mathrm{mg} / \mathrm{mL})$. The percentage inhibition was calculated by the formula given bellow: $\left[\left(\mathrm{A}_{0}-\mathrm{A}_{1} /\right.\right.$ $\left.\left.A_{0}\right) \times 100\right]$ in which $A_{1}$ and $A_{0}$ are absorbances of solvent with and without sample, respectively. The results were expressed as the mean $\pm \mathrm{SD}(\mathrm{mg} / \mathrm{mL})$ of three $\mathrm{IC}_{50}$ values (replicates).

\section{FTIR-ATR (Fourier-transform infrared- attenuated total reflection) analysis}

Honey samples were also analysed with FTIR-ATR spectroscopy. The spectral information was acquired in accordance with the procedure previously reported (Anjos et al. 2015) with Bruker spectrometer (Alpha) using a diamond single reflection attenuated total reflectance device. For spectra for different aliquot of the same samples were obtained with 32 scans per spectrum at a spectral resolution of $4 \mathrm{~cm}^{-1}$ in the wavenumber range from 4000 to $400 \mathrm{~cm}^{-1}$. Prior analysis several pre-treated were tested namely: standard normal variate (SNV), multiplicative scatter correction (MSC), normalize, centred and scaled, first derived Savitzky-Golay (1st derived), second derived Savitzky-Golay (2nd derived), baseline and several combinations of 2 pre-treatments, to identify the better one to use in the further analysis.

\section{Statistical analysis}

To compare the means of assessed parameters before and after the heat processing, paired student $t$ test was used. The difference was accepted to be statistically significant with $p<0.05$. The data processing was done on IBM SPSS Statistics 25 software.

Principal component analyses (PCA) with spectral information were performed using the Unscrambler ${ }^{\circledR} \mathrm{X}$, version: 10.5.46461.632 (CAMO Software AS, Oslo, Norway).

\section{Results and discussion}

\section{Effect of heat processing on the physicochemical parameters}

The application of thermal treatment on honey samples has been reported to affect highly its quality and it is proven that the kinetic of this process depends on the degree and heating time (Turhan et al. 2008). In this study, honey samples were heated at $121{ }^{\circ} \mathrm{C}$ for $30 \mathrm{~min}$ and the heat processing effect was confirmed indirectly through the assessment of a panel of physicochemical parameters including hydroxymethylfurfural content (HMF) and diastase activity (Table 1). The heat processing, in all the analysed samples, significantly increased $(p<0.01)$ the HMF content and the mean values changed from $7.70 \pm 5.82$ to $20.11 \pm 11.91 \mathrm{mg} / \mathrm{kg}$. Both values are below $40 \mathrm{mg} / \mathrm{kg}$ which is the maximum allowed by the Codex Alimentarius for the HMF content in honey (Codex Alimentarius Commission 2001). In spite of that, the HMF content increased around $55 \%$ with the thermal processing what is a very significant quick increase. (Turhan et al. 2008) reported the same pattern in floral honey submitted to a similar treatment $\left(100{ }^{\circ} \mathrm{C}\right.$ for $\left.30 \mathrm{~min}\right)$ and suggested that the increase in the HMF content is more likely to be sensitive to primitive storage conditions rather than to overheating.

As expected, the use of decomposition heat processing by Tosi et al. (2008) induced a drastic decrease in the diastase activity: the recorded value changed from $21.31 \pm 5.94$ shade unit/g in raw samples to values bellow the detection limits following processing. Theoretically, a process of proteins' decomposition induces an increase in the free fraction of amino acids, including the proline. In contrast, the presence of a digestion step (sulphuric acid and thermal treatment) in the process of quantifying the proline content suppresses the ability to see this increase. On the contrary, a decrease was seen in the proline content of the analysed samples after the heat processing, yet this result was not significant (Table 1).

In the present study, HMF, proline, diastase activity, honey colour, melanoidins, polyphenols and flavonoids contents were assessed. All these parameters changed after honeys' heating, although statistical significance was not always reached. The honey colour increased 38\% in $\mathrm{mm}$ pfund while the melanoidins' content increased by $28 \%$. Both parameters are directly linked to the core of this study, as they provide a tool to assess the formation of the brown pigments of the Millard reaction, known to occur in honey following a thermal treatment (Wang et al. 2011). Both parameters showed a highly significant increase $(p<0.001)$, and their values increase from $60.94 \pm 30.67$ to $83.92 \pm 29.98$ pfund for the colours and from $0.98 \pm 0.38$ to $1.25 \pm 0.44$ for melanoidins content.

It has been reported that the polyphenols and flavonoids contents are involved in the antioxidant activities of honey (Brudzynski and Miotto 2011a). Therefore, these compounds were assessed as quick predictive indicators of the changes occurring in antioxidant activities', either lost or acquired. It was observed, although, that the polyphenols' contents did not vary significantly with the heat treatment. 
Table 1 The physicochemical characterization and the antioxidant activities of honey sample before and after heat processing

\begin{tabular}{|c|c|c|c|c|}
\hline \multirow[t]{2}{*}{ Parameter } & \multicolumn{2}{|c|}{ Raw honey samples } & \multicolumn{2}{|c|}{ After heat processing } \\
\hline & Mean \pm SD & Range & Mean & Range \\
\hline Proline (mg/kg) & $817.10 \pm 104.59$ & 709.95-1007.49 & $773.65 \pm 141.68$ & 593.63-994.15 \\
\hline HMF (mg/kg) & $7.70 \pm 5.82$ & $1.07-15.97$ & $20.10 \pm 11.91$ & $8.73-38.57$ \\
\hline Diastase (Shade number) & $21.31 \pm 5.94$ & $11.33-30.30$ & - & - \\
\hline Colour (mm pfund) & $60.94 \pm 30.67$ & $28.46-116.91$ & $83.92 \pm 29.98$ & $54.75-131.58$ \\
\hline Melanoidins & $0.98 \pm 0.38$ & $0.56-1.55$ & $1.25 \pm 0.44$ & $0.74-1.88$ \\
\hline Water content $(\%)$ & $18.97 \pm 1.25$ & $17.27-20.40$ & $18.35 \pm 0.77$ & $17.27-19.13$ \\
\hline Polyphenol (mg GAE/100 g) & $96.05 \pm 26.55$ & $63.44-130.04$ & $96.78 \pm 25.36$ & $67.27-132.61$ \\
\hline Flavonoids mg CE/100 g & $23.70 \pm 4.89$ & $17.12-29.32$ & $20.44 \pm 3.41$ & $14.52-25.59$ \\
\hline TAA (mg EAA/g Honey) & $370.44 \pm 51.97$ & $278.53-442.68$ & $377.25 \pm 48.54$ & $294.60-433.12$ \\
\hline $\mathrm{DPPH}\left(\mathrm{IC}_{50} \mathrm{mg} / \mathrm{mL}\right)$ & $15.34 \pm 7.55$ & $7.94-27.13$ & $12.70 \pm 4.61$ & $6.45-19.69$ \\
\hline $\mathrm{ABTS}^{+} \mathrm{IC}_{50}(\mathrm{mg} / \mathrm{mL})$ & $7.00 \pm 2.79$ & $4.20-12.18$ & $5.60 \pm 2.10$ & $3.53-9.26$ \\
\hline Chelating Power $\mathrm{IC}_{50}(\mathrm{mg} / \mathrm{mL})$ & $46.11 \pm 42.39$ & $7.98-132.19$ & - & - \\
\hline Reducing power (Max Abs) & $1.77 \pm 0.40$ & $1.29-2.34$ & $1.48 \pm 0.17$ & $1.21-1.74$ \\
\hline Superoxide $\left(\mathrm{IC}_{50} \mathrm{mg} / \mathrm{mL}\right)$ & $50.91 \pm 28.30$ & $15.02-88.43$ & $50.88 \pm 22.81$ & $24.05-85.90$ \\
\hline Nitric oxide $\left(\mathrm{IC}_{50} \mathrm{mg} / \mathrm{mL}\right)$ & $125.89 \pm 39.28$ & $81.98-189.60$ & $161.45 \pm 43.37$ & $110.81-222.83$ \\
\hline
\end{tabular}

-, without activity

Only the flavonoids content decreased significantly $(p<0.01)$ after the thermal treatment (around 14\%). A significant decrease in the content of some flavonoids and polyphenolic acids had been reported $(p<0.05)$ following the industrial pasteurization process (Escriche et al. 2014).

\section{Effect of thermal treatment on the antioxidant activities}

The effect of heat processing on the antioxidant activities is also presented in Table 1. Results are expressed as mean of all analysed samples for a given parameter, and the difference between the means was evaluated using a student $t$ test.

The antioxidant activity assessed through the DPPH methodology increased after the thermal treatment, with a decrease of the $\mathrm{IC}_{50}$ values from $15.34 \pm 7.55$ to $12.70 \pm 4.61 \mathrm{mg} / \mathrm{mL}$ (Table 1). Even though this increase was not significant in the present study, the same behaviour was reported previously in heather honey heated at $95{ }^{\circ} \mathrm{C}$ for 5 min (Kowalski 2013). The same authors reported that the increase was more pronounced in acacia honey samples $(p<0.05)$, suggesting that the change in the antioxidant activity following thermal treatment is influenced by the botanic origin of honey samples.

Similar results were obtained for the $\mathrm{ABTS}^{+}$antioxidant assay, where an increasing of $20 \%$ in the activity was observed after the heat processing. Still, in contrast to the registered in the DPPH assay, this difference was significant $(p<0.05)$. Both assays are used to evaluate the free radical scavenging capacity, but the $\mathrm{ABTS}^{+}$is more likely to be used for honey samples since aqueous solutions were used and the DPPH assay is strongly influenced by the solvent whereas the $\mathrm{ABTS}^{+}$method can be used in hydrophilic and lipophilic samples (Magalhães et al. 2008).

The heat processing applied in this study could abolish the ability of samples to chelate the iron ions. Indeed, following the chelating power experimental procedure the $\mathrm{IC}_{50}$ of the thermally treated samples could not be determined, in opposite to what occurred with raw fresh samples where $\mathrm{IC}_{50}$ was of $46.11 \pm 42.39 \mathrm{mg} / \mathrm{mL}$. Organic acid and flavonoids are known to possess metal chelating activity (Chua et al. 2013). Therefore, the observed decrease in flavonoids content along with a possible deterioration of organic acids (not determined in the present work) may have an influence in the observed effect on iron chelating power after the thermal treatment. Previous study on Zantaz honey reported a correlation between chelating activity from one side and proline and diastase activity from the other side (Elamine et al. 2018). This relationship can be seen in the present contribution as both proline and diastase activity was seen after the heat processing.

The ability of honey samples to reduce the ferric ions was another activity that was negatively affected by the heat processing, reaching a value of $1.48 \pm 0.17$ (absorbance of the highest used concentration) compared to $1.77 \pm 0.40$ of the raw samples (Table 1); although, this difference did not achieve the level of significance (Table 1). 


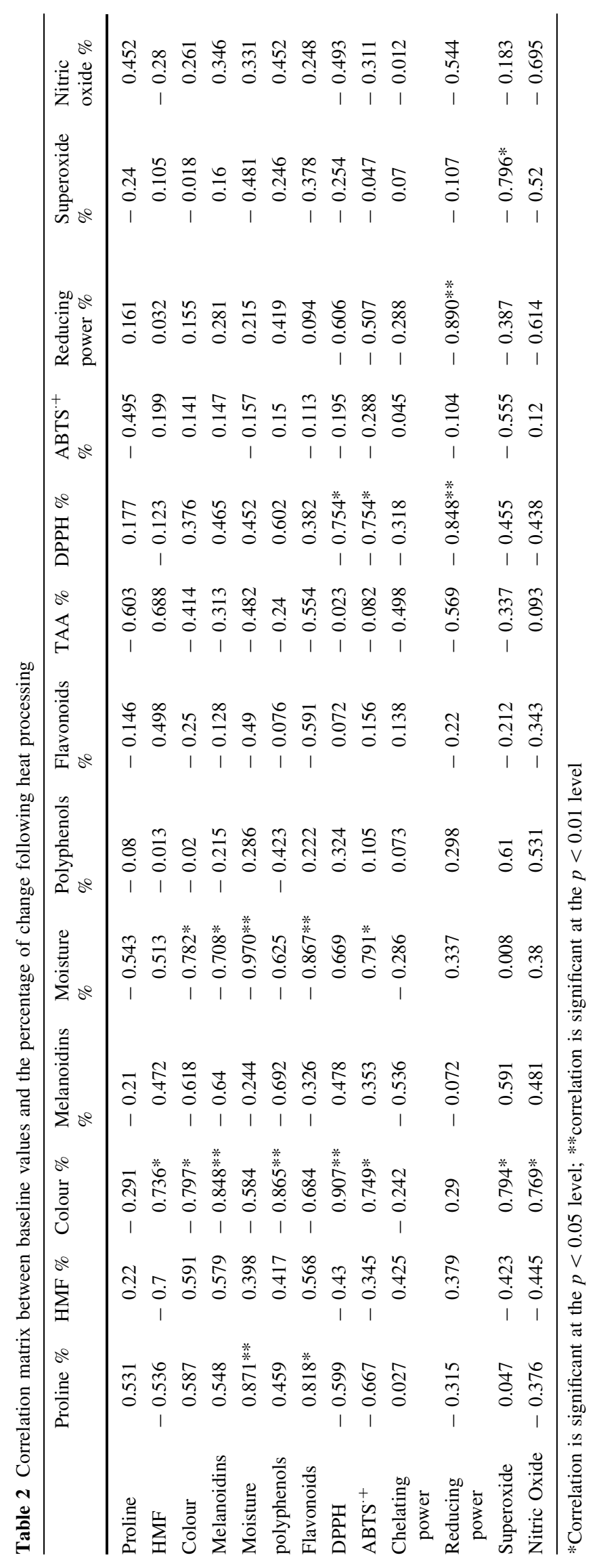



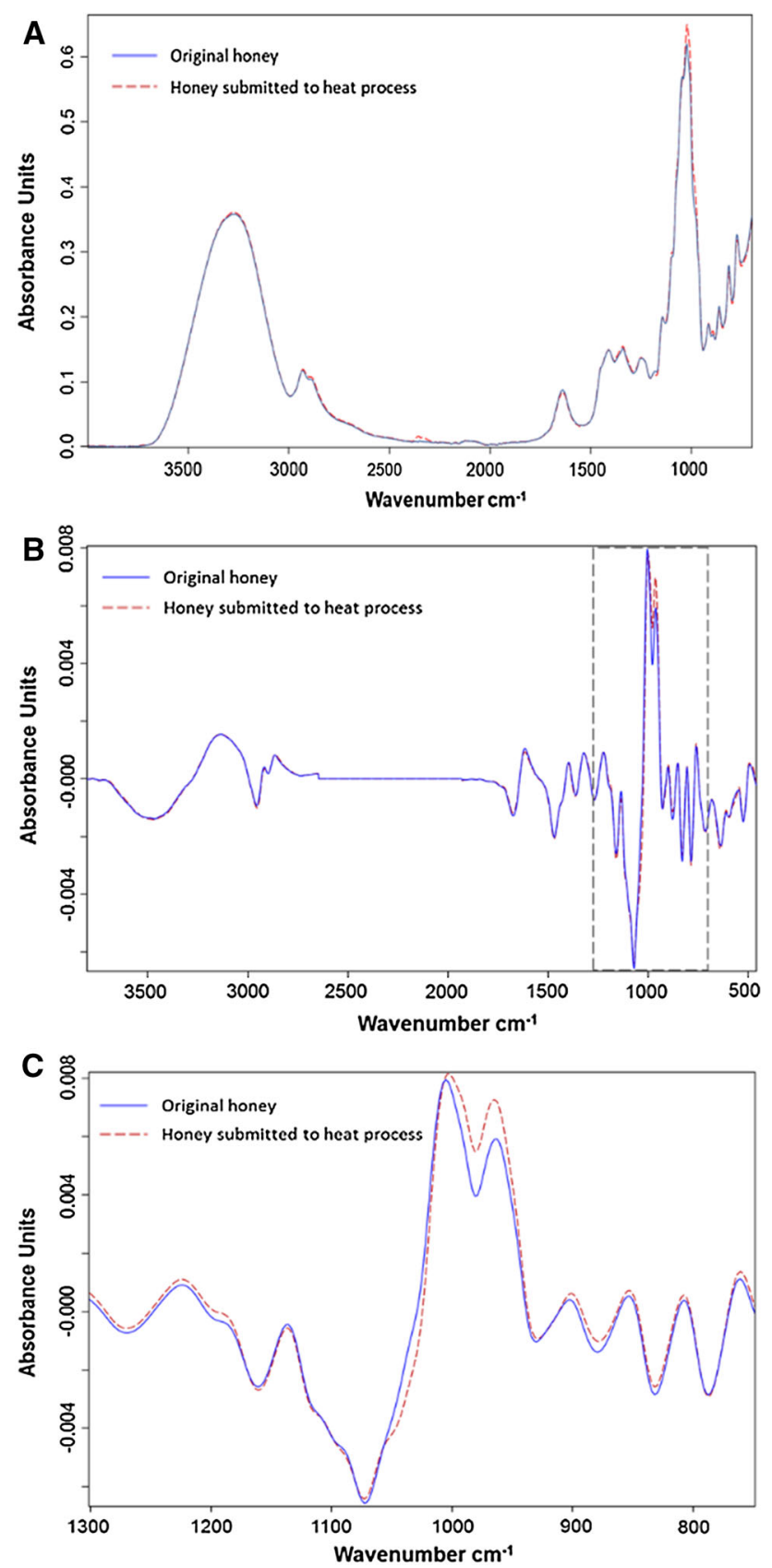

Fig. 1 FTIR-ATR spectra for honey samples with and without heating. a Average spectra obtained by FTIR-ATR, for honey with and without heating, b processed FTIR-ATR (all spectra), c processed FTIR-ATR (region used in the analysis)

The heat processing negatively affected $(p<0.01)$, the ability of Zantaz honey samples to scavenge the NO free radicals. The corresponding $\mathrm{IC}_{50}$ values increased from $125.89 \pm 39.28$ (in the raw unprocessed samples) to $161.45 \pm 43.37 \mathrm{mg} / \mathrm{mL}$ (in honey samples submitted to heating). Such important decrease of the NO scavenging assay could be explained by the reduction of flavonoids content as a strong correlation between the two parameters

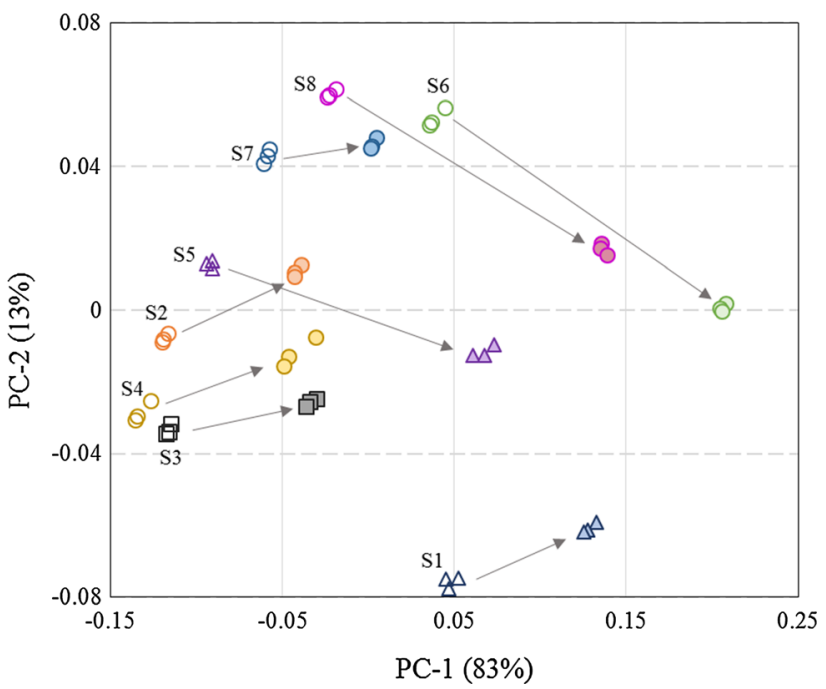

Fig. 2 Score plot of two principal components from raw spectral data acquire with FTIR-ATR data of honey based on: a marks without fill correspond to honey samples without heat processing, $\mathbf{b}$ marks filled belong to samples after heat processing from 800 to $1250 \mathrm{~cm}^{-1}$

was already reported in honey (Dor and Mahomoodally 2014).

As for the superoxide activity, no significant changes were observed and the $\mathrm{IC}_{50}$ values were $50.91 \pm 28.30 \mathrm{mg} / \mathrm{mL}$ before the heat processing and $50.88 \pm 22.81 \mathrm{mg} / \mathrm{mL}$ after the heating process. The stability seen in this antioxidant assay suggests that the responsible compounds, did not suffer the consequences of the heat treatment. Polyphenols evaluated by the FolinCiocalteu method remained also constant after heat processing which may be an explanation to the behaviour of superoxide activity. It is worth mentioning that high polyphenolic contents in honey are linked to high superoxide scavenging activity (Uthurry et al. 2011). In Manuka honey, the superoxide activity was due mostly to the presence of one phenolic compound, methyl syringate (Inoue et al. 2005).

Table 2 illustrates the correlation matrix between the initial values obtained for the assessed parameters and the percentage of the changes within the same parameters following heat processing. The honey colour seems to be the most affected parameter, as a negative correlation could be seen between honey colour changes after heat processing, from one side; and the baseline values of colour $(p<0.05)$, melanoidins $(p<0.01)$, polyphenols $(p<0.01)$, and HMF $(p<0.05)$, from the other side. In addition, the same parameter had also a positive correlation with the $\mathrm{IC}_{50}$ obtained with DPPH $(p<0.01), \mathrm{ABTS}^{+}$ $(p<0.05)$, superoxide $(p<0.05)$ and nitric oxide $(p<0.05)$ antioxidant activities.

Other feature that could be observed in the correlation matrix is the effect of the initial antioxidant activity and the 

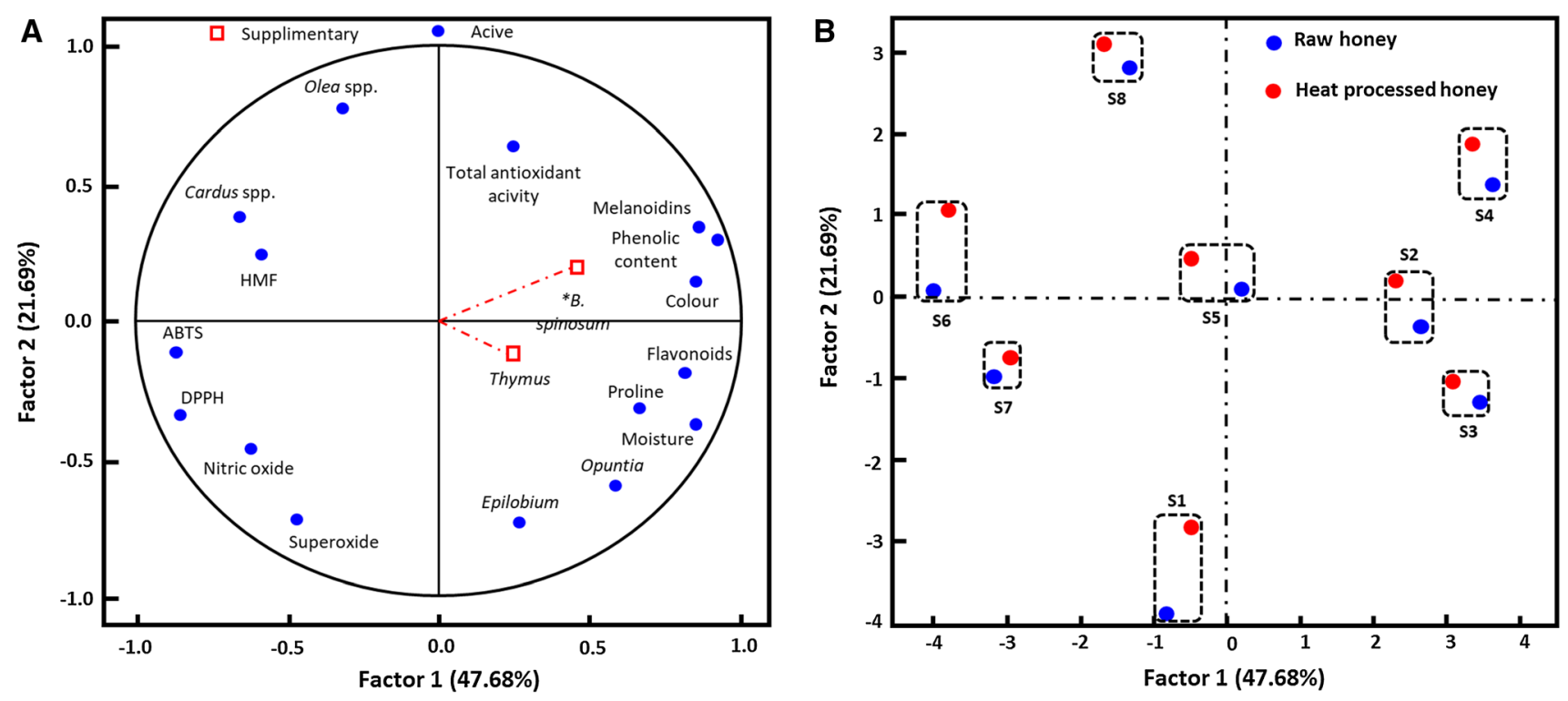

Fig. 3 Plot of two principal components from all analysed parameter (a) and scores (b) processing. Each rectangle refers to one honey sample before and after heat processing

resulting changes in such activity following heat processing. Negative correlations were obtained in the case of DPPH $(p<0.05)$, reducing power $(p<0.01)$ and superoxide $(p<0.05)$ antioxidant activities.

Higher percentages of colour changes were observed on honeys that were lighter prior heating. Similarly, higher colour changes occurred following heating in samples with baseline lower amounts of melanoidins and polyphenols, as well as lower capacity for scavenging DPPH, ABTS ${ }^{+}$, superoxide and NO free radicals. Changes in the chemical and antioxidant attributes of honey after heating had already been reported (Nagai et al. 2001; Brudzynski and Miotto 2011a). The results of the present work suggest that heating lighter honey, honey with lower amounts of polyphenols, or with lower antioxidant activity induces more accentuated changes than those observed in darker honeys or those already possessing higher amounts of polyphenols or higher antioxidant activity.

\section{Effect of heating evaluated by FTIR-ATR analysis}

The spectra obtained for the honey samples, represented in Fig. 1a, are similar to those obtained by other authors (de Ribeiro et al. 2014; Anjos et al. 2015).

The spectra were considered adequate for analysis when the difference between spectra for a particular sample was lower than 0.002 for 10 spectra. First derived SavitzkyGolay (1st derived) was used as pre-processed in the region between 1300 and $800 \mathrm{~cm}^{-1}$ (Fig. 1b, c). The validation method used was the cross-validation method. The criteria used to classify the samples was a ratio of calibrated to validated residual variance of 0.5 ; ratio of validated to calibrated residual variance of 0.75 and residual variance increase limit of $6 \%$.

In a first screening, a PCA with all spectral regions (from 4000 to $400 \mathrm{~cm}^{-1}$ ) was performed. However, better results were obtained when the region from 800 to $1250 \mathrm{~cm}^{-1}$ was used as shown in the Fig. 2. In this case, it was observed an important spectral resolution in relation to the heating process that was explained by the PC- 1 (83\% of the total variation). Furthermore, in Fig. 2, it is also observed a different behaviour for the different species, that could be explain by the effect of the botanical origin as explained before. The honey samples are all classified as Zantaz honey, but the secondary nectar plays also an important influence.

In order to better understand the influence of the botanical origin and the importance of the antioxidant activities in the differentiation of honey samples, a second PCA was performed with the data collected in this work and the secondary bee pollen observed in the honey samples (between 15 and 45\%) (Fig. 3).

In the Fig. $3 \mathrm{a}$ it is possible to understand the effect of presence of the secondary pollen grains namely Cardus spp., Olea spp. and Opuntia spp. in the antioxidant activity of different honey samples. The quantity of pollen of $B$. spinosum does not show to have principal role in discriminating honey samples. although samples located in the same direction as it does, showed to move to the right considering the first factor. Those samples are S2, S3, S4, S5 and S8. In contrast honey samples S1, S4 and S7 moved to the opposite direction. This suggest that B. spinosum pollen is important in determining a honey samples behaviour after heat processing. The scores plot (Fig. 3b) show 
similar results to those observed in the Fig. 2. There are differences between the samples after and before heating process; however, this variation was explained by the Factor 2 that explained only $21.7 \%$ of the total variance. Therefore, the spectral variance observed is influenced by the degradation of the polyphenolic compounds but also related to the degradation of sugar by the Maillard reaction, also well explained by Brudzynski and Miotto (2011a).

\section{Conclusion}

The existence of different tendencies amongst the assessed antioxidant activities following the thermal treatment suggests that each one is governed by distinct molecule or group of molecules. Additionally, radicals without homologies in biological systems, namely DPPH and $\mathrm{ABTS}^{+}$, were increased by the heat processing. On the contrary, the capacity for scavenging NO radicals was reduced after heating honey samples; this may indicate that the ability of heated honey to scavenge this important mediator of the inflammation is reduced. Furthermore, the chelating ability of honey samples was totally removed by the heat processing. The antioxidant capacity of honey after heating is therefore also dependent on the method used for evaluating this property. Overall, it seems that heating Zantaz honey will not improve the antioxidant activity, at least when this biological property is assessed by the methodologies hereby reported. While a confirmation is needed for honeys with other floral origins, it may be important to avoid heat processing for samples destined for being applied in circumstances where the oxidative stress plays a role.

Acknowledgements Thanks are due to Foundation for Science and Technology FCT, Portugal (FCT/MCTES) for the financial support to MeditBio (UIDB/05183/2020), CEF (Centro de Estudos Florestais (UIDB/00239/2020) and CIMO (Centro de Investigação de Montanha), Instituto Politécnico de Bragança (UID/AGR/00690/2019).

Author contributions OA, LME, BL, SA and MGM conceived and designed research; YE, OA, LME and MGM wrote the manuscript: YE, OA, LME and MGM conducted the experiments. MGM, OA and LME supervised the work. All authors read and approved the manuscript.

\section{Compliance with ethical standards}

Conflict of interest The authors declare no conflict of interest.

\section{References}

Abu-Jdayil B, Al-Majeed Ghzawi A, Al-Malah KIM, Zaitoun S (2002) Heat effect on rheology of light- and dark-colored honey.
J Food Eng 51(1):33-38. https://doi.org/10.1016/S02608774(01)00034-6

Albano SM, Miguel MG (2011) Biological activities of extracts of plants grown in Portugal. Ind Crops Prod 33:338-343. https:// doi.org/10.1016/j.indcrop.2010.11.012

Anjos O, Campos MG, Ruiz PC, Antunes P (2015) Application of FTIR-ATR spectroscopy to the quantification of sugar in honey. Food Chem 169:218-223. https://doi.org/10.1016/j.foodchem. 2014.07.138

Bogdanov S, Martin P, Lüllmann C, Borneck R, Ch Flamini C, Morlot M, Ivanov T (2009) Harmonised methods of the international honey commission

Brand-Williams W, Cuvelier ME, Berset C (1995) Use of a free radical method to evaluate antioxidant activity. LWT Food Sci Technol 28(1):25-30. https://doi.org/10.1016/S00236438(95)80008-5

Brudzynski K, Miotto D (2011a) Honey melanoidins: analysis of the compositions of the high molecular weight melanoidins exhibiting radical-scavenging activity. Food Chem 127(3):1023-1030. https://doi.org/10.1016/j.foodchem.2011.01.075

Brudzynski K, Miotto D (2011b) The recognition of high molecular weight melanoidins as the main components responsible for radical-scavenging capacity of unheated and heat-treated Canadian honeys. Food Chem 125(2):570-575. https://doi.org/10. 1016/j.foodchem.2010.09.049

Brudzynski K, Miotto D (2011c) The relationship between the content of Maillard reaction-like products and bioactivity of Canadian honeys. Food Chem 124(3):869-874. https://doi.org/10.1016/j. foodchem.2010.07.009

Chu Y, Chang C, Hsu H (2000) Flavonoid content of several vegetables and their antioxidant activity. Food Sci Technol 566(September 1999):561-566. https://doi.org/10.1002/ (SICI) 1097-0010(200004)80:5\%3c561:AID-JSFA574\%3e3.0. $\mathrm{CO} ; 2-\% 23$

Chua LS, Rahaman NLA, Adnan NA, Eddie Tan TT (2013) Antioxidant activity of three honey samples in relation with their biochemical components. J Anal Methods Chem. https:// doi.org/10.1155/2013/313798

Codex Alimentarius Commission (2001) Codex Alimentarius Commission Standards. Codex Stan 12-1981, pp 1-8. https://doi.org/ 10.1007/978-3-540-88242-8

Da Silva PM, Gauche C, Gonzaga LV, Costa ACO, Fett R (2016) Honey: chemical composition, stability and authenticity. Food Chem 196:309-323. https://doi.org/10.1016/j.foodchem.2015. 09.051

de Ribeiro ROR, Mársico ET, de Jesus EFO, da Silva Carneiro C, Júnior CAC, de Almeida E, do Filho VF (2014) Determination of trace elements in honey from different regions in Rio de Janeiro state (Brazil) by total reflection X-ray fluorescence. J Food Sci 79(4):738-742. https://doi.org/10.1111/1750-3841.12363

Dor GOLM, Mahomoodally MF (2014) Chemical profile and in vitro bioactivity of tropical honey from Mauritius. Asian Pac J Trop Dis 4(S2):S1002-S1013. https://doi.org/10.1016/S22221808(14)60773-8

Elamine Y, Aazza S, Lyoussi B, Dulce Antunes M, Estevinho LM, Anjos O, Resende M, Faleiro ML, Miguel MG (2018) Preliminary characterization of a Moroccan honey with a predominance of Bupleurum spinosum pollen. J Apic Res. https://doi.org/10. 1080/00218839.2016.1265759

Elamine Y, Lyoussi B, Anjos O, Estevinho LM, Aazza S, Carlier JD, Costa MC, Miguel MG (2019) Zantaz honey "monoflorality": chemometric applied to the routinely assessed parameters. LWT Food Sci Technol 106:29-36. https://doi.org/10.1016/j.lwt.2019. 02.039

Escriche I, Kadar M, Juan-Borrás M, Domenech E (2014) Suitability of antioxidant capacity, flavonoids and phenolic acids for floral 
authentication of honey. Impact of industrial thermal treatment. Food Chem 142:135-143. https://doi.org/10.1016/j.foodchem. 2013.07.033

Escuredo O, Rodríguez-Flores MS, Rojo-Martínez S, Seijo MC (2019) Contribution to the chromatic characterization of unifloral honeys from Galicia (NW Spain). Foods 8(7):233. https://doi. org/10.3390/foods8070233

Ho SC, Tang YL, Lin SM, Liew YF (2010) Evaluation of peroxynitrite-scavenging capacities of several commonly used fresh spices. Food Chem 119(3):1102-1107. https://doi.org/10. 1016/j.foodchem.2009.08.020

Inoue K, Murayama S, Seshimo F, Takeba K, Yoshimura Y, Nakazawa H (2005) Identification of phenolic compound in manuka honey as specific superoxide anion radical scavenger using electron spin resonance (ESR) and liquid chromatography with coulometric array detection. J Sci Food Agric 85(5):872-878. https://doi.org/10.1002/jsfa.1952

Kowalski S (2013) Changes of antioxidant activity and formation of 5-hydroxymethylfurfural in honey during thermal and microwave processing. Food Chem 141(2):1378-1382. https://doi.org/ 10.1016/j.foodchem.2013.04.025

Louveaux J, Maurizio A, Vorwohl G (1978) Methods of Melissopalynology. Bee World 5:139-153. https://doi.org/10.1080/ 0005772X.1978.11097714

Magalhães LM, Segundo MA, Reis S, Lima JLFC (2008) Methodological aspects about in vitro evaluation of antioxidant properties. Anal Chim Acta 613(1):1-19. https://doi.org/10.1016/j. aca.2008.02.047

Miguel MG, Nunes S, Dandlen SA, Cavaco AM, Antunes MD (2010) Phenols and antioxidant activity of hydro-alcoholic extracts of propolis from Algarve, South of Portugal. Food Chem Toxicol 48(12):3418-3423. https://doi.org/10.1016/j.fct.2010.09.014

Naab OA, Tamame MA, Caccavari MA (2008) Palynological and physicochemical characteristics of three unifloral honey types from central Argentina. Span J Agric Res 6(4):566-576

Nagai T, Sakai M, Inoue R, Inoue H, Suzuki N (2001) Antioxidative activities of some commercially honeys, royal jelly, and propolis. Food Chem 75(2):237-240. https://doi.org/10.1016/ S0308-8146(01)00193-5

Prieto P, Pineda M, Aguilar M (1999) Spectrophotometric quantitation of antioxidant capacity through the formation of a phosphomolybdenum complex: specific application to the determination of vitamin E. Anal Biochem 269(2):337-341. https://doi.org/10.1006/abio.1999.4019
Salvador L, Guijarro M, Rubio D, Guill T, Jentzsch PV, Ciobot V, Stolker L, Ulic S, Vásquez L, Guerrero LR (2019) Exploratory monitoring of the quality and authenticity of commercial honey in Ecuador. Foods. https://doi.org/10.3390/foods8030105

Samatha T, Shyamsundarachary R, Srinivas P, Swamy NR (2012) Quantification of total phenolic and total flavonoid contents in extracts of Oroxylum indicum L. Kurz. Asian J Pharm Clin Res 5(SUPPL.4): 177-179

Sancho MT, Pascual-Maté A, Rodríguez-Morales EG, Osés SM, Escriche I, Periche Á, Fernández-Muiño MA (2016) Critical assessment of antioxidant-related parameters of honey. Int $\mathrm{J}$ Food Sci Technol 51(1):30-36. https://doi.org/10.1111/ijfs. 12988

Shapla UM, Solayman M, Alam N, Khalil MI, Gan SH (2018) 5-Hydroxymethylfurfural (HMF) levels in honey and other food products: effects on bees and human health. Chem Cent J 12(1):35. https://doi.org/10.1186/s13065-018-0408-3

Singleton VL, Rossi JA Jr (1965) Colorimetry of total phenolics with phosphomolybdic-phosphotungstic acid reagents. Am J Enol Vitic 16(3):144-158. https://doi.org/10.12691/ijebb-2-1-5

Tosi E, Ciappini M, Ré E, Lucero H (2002) Honey thermal treatment effects on hydroxymethylfurfural content. Food Chem 77(1):71-74. https://doi.org/10.1016/S0308-8146(01)00325-9

Tosi E, Martinet R, Ortega M, Lucero H, Ré E (2008) Honey diastase activity modified by heating. Food Chem 106(3):883-887. https://doi.org/10.1016/j.foodchem.2007.04.025

Turhan I, Tetik N, Karhan M, Gurel F, Reyhan Tavukcuoglu H (2008) Quality of honeys influenced by thermal treatment. LWT Food Sci Technol 41(8):1396-1399. https://doi.org/10.1016/j.lwt. 2007.09.008

Turkmen N, Sari F, Poyrazoglu ES, Velioglu YS (2006) Effects of prolonged heating on antioxidant activity and colour of honey. Food Chem 95(4):653-657. https://doi.org/10.1016/j.foodchem. 2005.02.004

Uthurry CA, Hevia D, Gomez-Cordoves C (2011) Role of honey polyphenols in health. $\mathrm{J}$ ApiProduct ApiMedical Sci 3(4):141-159. https://doi.org/10.3896/ibra.4.03.4.01

Wang HY, Qian H, Yao WR (2011) Melanoidins produced by the Maillard reaction: structure and biological activity. Food Chem 128(3):573-584. https://doi.org/10.1016/j.foodchem.2011.03. 075

Publisher's Note Springer Nature remains neutral with regard to jurisdictional claims in published maps and institutional affiliations. 